\title{
Assessment of the Influence Process Parameters in the Friction Stir Welded Mechanical and Corrosion Properties of AA5754 Alloys
}

\author{
F. Nascimento ${ }^{1}$, P. Vilaça ${ }^{2}$, R. Miranda ${ }^{3}$, J. C. S. Fernandes ${ }^{4}$ and F. M. Andrade Pires ${ }^{5}$ \\ ${ }^{1}$ Faculdade de Engenharia at Universidade do Porto, Porto, Portugal \\ ${ }^{2}$ Department of Engineering Design and Production, School of Engineering, \\ Aalto University, Finland \\ ${ }^{3}$ FCT-UNL, Faculty of Science and Technology, Universidade Nova de Lisboa, \\ Monte da Caparica, Portugal \\ ${ }^{4}$ DEQ / ICEMS, Instituto Superior Técnico, Universidade Técnica de Lisboa, \\ Lisboa, Portugal \\ ${ }^{5}$ Faculdade de Engenharia at Universidade do Porto, Porto Pormgal \\ lf.nascimento@sapo.pt, 2pedro.vilaca@aalto.fi.rmiranda@fct.unl.pt, \\ joao.salvador@ist.utl.pt, 5 fpires@fe.up.pt
}

Abstract
Friction Stir Welding (FSW) has been applied to AA5754 HOl alloy. An in-depth analysis of the influence of the process parameters has been performed using Taguchi method. Through the optimization of the proces parameter thas been observed what the best process conditions for the different mechanical properties. It was observed that for tensile properties the best that lower advancing speeds and lower applied forces would be more beneficial to obtain a better tensile behavior. On the other hand, the higher advancing speeds and higher applied forces have proven to give a better bending behavior. The optimization algorithm has proven to be efficient giving welded samples with $98 \%$ efficiency, very close to the base material behdvior. The corrosion testing has proven that these alloys are very resistant to corrosion although some caytion should be taken regarding the "root defect".

Keywords Aluminium alloys, Friction Stir Welding, Corrosion testing, Taguchi Method

\section{Introduction}

Nowadays one of the main goals in the in several industries is the reduction of the carbon emissions. In the automotive industry this can be obtained through the reduction of the fuel consumption during a car drive or by the development of more efficient engines where the energy losse from heat are decreased [1]. Our work is focused in the reduction of fuel reduction by introducing lighter solutions using materials that have a lower density than the usual-materials used in automotive applications.

FSW was invented by the Welding Institute (TWI) of the UK in 1991 as a solid state technology [2]. In this process a non-consumable tool composed by a pin and shoulder rotates and after reaching a predefined position it moves in a transverse direction [3]. The improvement of properties is related to grain size refinement and homogenization due to the large processing strains in the nugget [4]. Cavaliere et al., [5] studied the evolution of the microstructure and mechanical properties of an AA6082 alloy with the different process parameters. It was observed that the grain size decreased with an increasing transverse speed. These results are aligned with the FSW principles because with the increasing transverse 
speed.

Several authors [6-8] have studied the effects of FSW parameters in in deffirent aluminium alloys to understand the best parameters to have the best joining efficiency of a weld. It was observed that the joining of different aluminiums is possible and that the properties are usually between the properties of the base materials [9-10]. Most studies have been focused to understand how the parameters influence the properties of the welded samples. This creates a need for a structured approach that can help in understanding the interaction between the welded samples properties and process parameters. Taguchi method is a method to do that and it has been applied to other friction stir processed aluminium alloys $[11,12]$ however no definite relationship has been established in these studied alloys. This study aims to learn the relationships between the process parameters and material properties. The second goal focuses on the behavior of the welded samples to corrosion environments.

\section{Experimental Procedure}

Sheets of AA5754-H111 with 2mm (Table 1) thickness wete friction stir welded using a tool with a scrolled shoulder and a threaded conic pin (Figure 1). The shoulder had a diameter of $15 \mathrm{~mm}$ and has a variable pin depth. The pin has a $4 \mathrm{~mm}$ diameter in the base that decreases to $3 \mathrm{~mm}$ in the tip. Different process variables (mainly adyancing speed $(\mathrm{V})$, applied force $(\mathrm{F})$ and Pin Length (L)) were investigated in order to identify the best variables for these alloys. Table 2 resumes the variable parameters that were tested in thiswork.

Table 1. Mechanical Properties of the AA5754-H111 Alloy

\begin{tabular}{|c|c|c|c|c|c|c|}
\hline & & & & \multicolumn{3}{|c|}{ Bending } \\
\hline E (GPa) & $\sigma y(M P a)$ & бUTS (MPa) & $A(\%) U T(J / m 3)$ & $\mathbf{F}(\mathbf{N})$ & d (mm) & $\mathbf{U B}(\mathbf{J})$ \\
\hline 45 & 128.83 & 241.56 & $19.93 \% \quad 44388.38$ & 1985 & 15.03 & 24675 \\
\hline
\end{tabular}

On the other hand, other parameters were kept constant in our studies the tool rotation speed of $800 \mathrm{rpm}$, the plunge speed of $01 \mathrm{~mm} / \mathrm{s}$, a the dwell time of $6 \mathrm{~s}$ and a pitch angle of $0^{\circ}$. Samples were metallurgically characterized using Keller's reagent composed by $2 \mathrm{~mL} \mathrm{HF}$, $3 \mathrm{ml} \mathrm{HCl}, 5 \mathrm{~mL} \mathrm{HNO}_{3}, 190 \mathrm{~mL} \mathrm{H}_{2} \mathrm{O}$.

Table 2. Test Parameters with Taguchi N9 Matrix

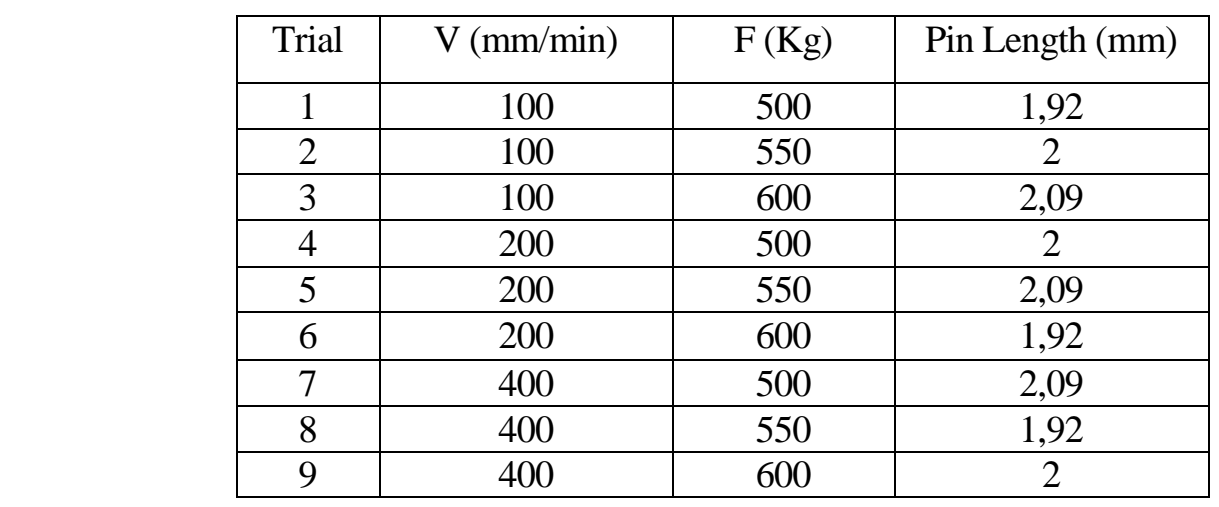




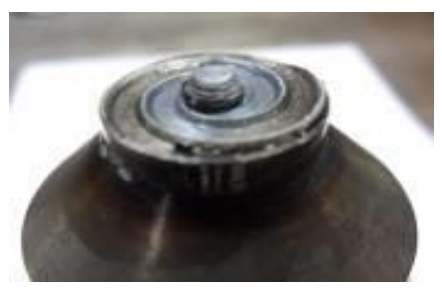

\section{Figure 1. FSW Tool with a Scrolled Shoulder a Threaded Conical Pin}

The samples were observed under optical microscopy. The samples were then tested under both tensile and flexion stress states. One of the samples was then subjected to corrosion testing to identify any corrosion mechanisms induced by this process. Samples submitted to tensile testing were made according to the ISO 10002 and the strain rate enforced was $5 \mathrm{~mm} / \mathrm{min}$. The results were analyzed using the Global Efficiency to Tensile Strengtb (GETS) (1). The GETS assesses the tensile strength efficiency of the welded joint (i) agamsit the base material (BM) properties. This coefficient was developed by Vilaça [13] and takes into account the different coefficients that are obtained from tensile testing. The GETS formula is given by:

$$
G E T S=C_{E} \frac{E_{i}}{E_{B M}}+C_{\sigma_{y}} \frac{\sigma_{y_{i}}}{\sigma_{y_{B M}}}+C_{\sigma_{U T S}} \frac{\sigma_{U T S_{i}}}{\sigma_{U T S_{B M}}}+C_{A} \frac{A_{i}}{A_{B M}}+C_{U_{T}} \frac{U_{T_{\text {BM }}}}{U_{\text {T }}}
$$

where $\mathrm{E}$ is the Young Modulus, $\sigma_{\mathrm{y}}$ is the yieldstress, $\sigma_{\mathrm{U}}$ is is the ultimate tensile stress, $\mathrm{A}$ is the elongation and $\mathrm{U}_{\mathrm{T}}$ is the toughness.

Table 3. Coefficients for GETS,GEB and Weid Efficiency Calculation

\begin{tabular}{|c|c|c|c|c|c|c|c|c|c|}
\hline \multicolumn{7}{|c|}{ GETS } & \multicolumn{3}{|c|}{$\%$ Weld } \\
\hline $\mathrm{C}_{\mathrm{E}}$ & $C_{\sigma y}$ & $\mathrm{C}_{\text {бUTS }}$ & $\mathrm{C}_{\mathrm{A}}$ & $a_{T}$ & $F(\mathrm{~N}) d(\mathrm{~mm})$ & $\mathbf{U B}(\mathbf{J})$ & $\mathbf{C}_{\text {GETS }}$ & $\mathbf{C}_{\mathrm{GEB}}$ & $\mathrm{C}_{\text {HARD }}$ \\
\hline 0.1 & 0.3 & 0.3 & 0.15 & 0.15 & 0.25 & 0.50 & 0.4 & 0.5 & 0.1 \\
\hline
\end{tabular}

Taking into that this intended application the following coefficients were considered (Table 3). Bending testing samples yere produced with a width of $20 \mathrm{~mm}$ and these samples were tested by using a strait rate of $6 \mathrm{~mm} / \mathrm{min}$. Similarly to GETS also an efficiency coefficient was created to evaluate the bending properties.

The Global efficiency to Bending (GEB) (2) assesses the bending efficiency of the welded joint (i) against the BMCproperties. In an analogy to the GETS, GEB takes into account the different coefficients that are obtained from bending testing. The GEB definition is given by:

$G E B=C_{F_{B}} \frac{F_{B i}}{F_{B M}}+C_{d} \frac{d_{i}}{d_{B M}}+C_{U_{B}} \frac{U_{B_{i}}}{U_{B_{B M}}}$ ף

where $\mathrm{F}$ is the maximum load, $\mathrm{d}$ is the displacement at maximum load and UB is the energy consumed until the beginning of fracture. The considered coefficients for the bending load are given in Table 3. A load of 500g was applied for the hardness testing and the hardness was measured in the mid-section of these samples. A total 21 indentations were performed in each measurement of the hardness profile of the samples. A Hardness Drop Ratio (HARD) was developed to relate the effect of the process and the heat release and its influence in the hardness properties. In this ratio the lowest hardness of the welded sample is compared with the average hardness of the base material. The weld efficiency (3) is the weighted average from the previous parameters and similar to the GETS and GEB, the weld efficiency is a coefficient of efficiency dependent of the application, which is given by: 


$$
\% \text { Weld }=C_{G E T S} G E T S+C_{G E B} G E B+C_{H A R D} H A R D \text { व }
$$

The coefficients for $\%$ Weld are also dependent on the application for this case it is expected that the part built will be submitted to several bending forces although the tensile forces are also present. The hardness is the parameter that has the lowest influence in the application and therefore will have the lowest coefficients. These coefficient values are given in Table 3. Corrosion testing was made according to the ASTM B117:11 standard. The samples were put in a saline environment and their corrosion behavior was tested for $350 \mathrm{~h}$. Both the front and back of the welded samples were tested. These samples were compared with the BM that was also included in the same batch.

\section{Results}

All tests in the Taguchi method were considered valid and this enables us to proceed with this optimization method. Also, a kissing bond was identified in the faster welds although no other major defect has been found in these samples. Figure 2 shows different boundary of the between the nugget and base material. The base material has an average hardness of $72.21 \pm 1.6$. It was observed that the welded samples with the same advancing had similar profiles between themselves. In Figure 3, it is presented the profiles between the samples which show an increase in hardness in the nugget region. The average hardness in the heat affected zone (HAZ) and BM is similar between the three samples.

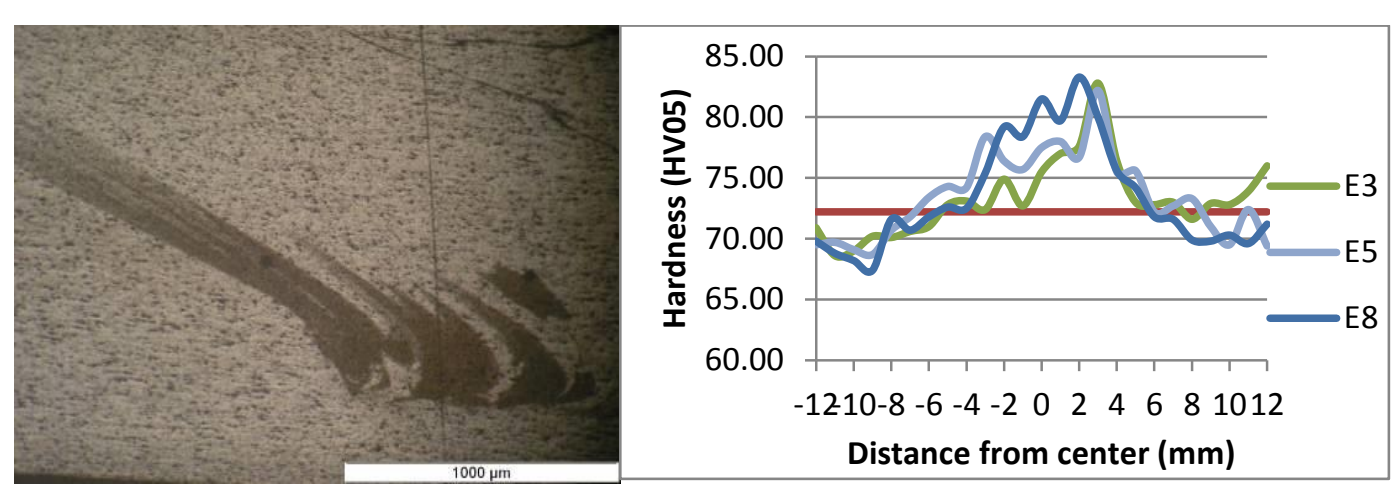

Figure 2. Micros ructure of the AA5754-H111 Welded

Figure 3. Hardness Profiles of the E3, E5 and E8 Trials

The hard efficiencies are given in Table 4 and show how he heat affected these alloys during the FSW process. It can be observed that the values of the hardness profiles are very similar between them and that this variation in hardness can be related to equipment error measurement.

Table 4. HARD, GETS and GEB Efficiencies for Welded Samples

\begin{tabular}{|c|c|c|c|c|c|c|c|c|c|}
\hline & E1 & E2 & E3 & E4 & E5 & E6 & E7 & E8 & E9 \\
\hline HARD & $88.5 \%$ & $97.8 \%$ & $95.0 \%$ & $94.2 \%$ & $95.1 \%$ & $89.9 \%$ & $93.8 \%$ & $93.3 \%$ & $87.9 \%$ \\
\hline GETS & $92.7 \%$ & $97.1 \%$ & $97.6 \%$ & $92.8 \%$ & $91.1 \%$ & $88.2 \%$ & $96.0 \%$ & $88.4 \%$ & $94.6 \%$ \\
\hline GEB & $94.8 \%$ & $103.2 \%$ & $104.0 \%$ & $104.3 \%$ & $102.3 \%$ & $102.1 \%$ & $105.4 \%$ & $104.2 \%$ & $105.3 \%$ \\
\hline
\end{tabular}




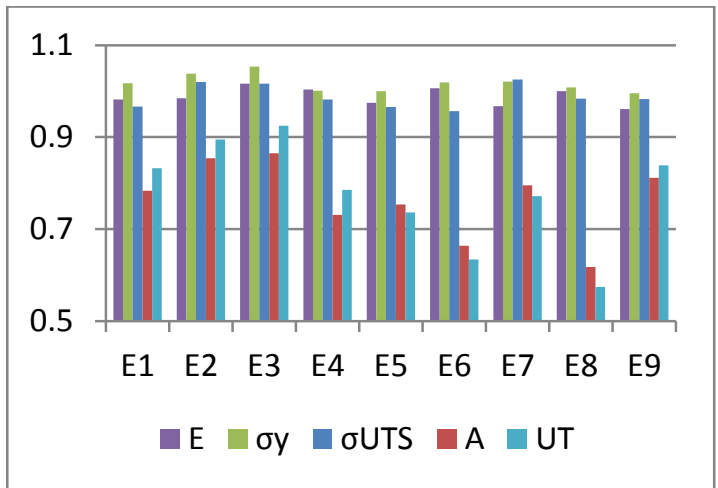

Figure 4. Influence of the GETS Parameters

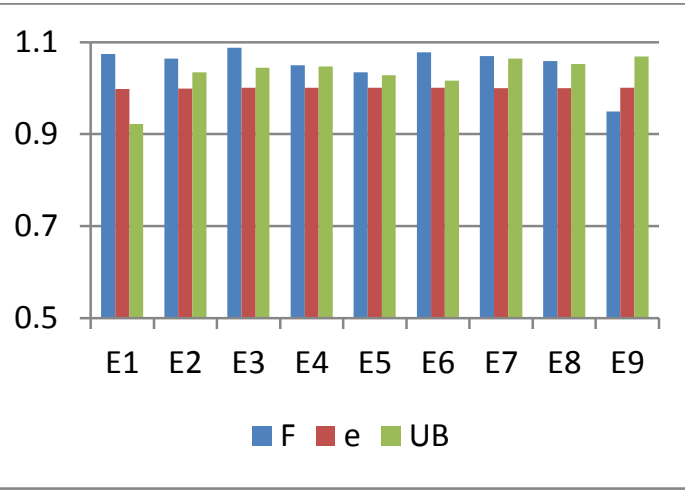

Figure 5. Influence of the GEB Parameters

The calculation of the GETS efficiency (Figure 4 and Table 6) has shown that the lowest advancing speeds have the best behavior regarding the efficiency. It also shows an improved efficiency for the bigger pin length. It can be clearly observed that the pin length has a great influence in the efficiency of the weld being emplasized the low efficiency visible in the trials with the lowest pin length.

The results from GEB (Figure 5 and Table 4 ) show that most trials have a performance better than the base material although E1 trialis below. Despite these results it was observed that in the faster welds with lower pin length it was visible a fissure in the bottom of the weld compliant with the "kissing bond" defecte

The three levels for each parameter are equally represented in the nine trials made. The planning of these is orthogonal which makes it possible to separate the effect of each in each level. Because of this, the average response of the parameter $\mathrm{x}$ in the level $\mathrm{Y}$ is given by the results obtained in the different trials with the parameter $\mathrm{X}$ at the level $\mathrm{Y}$. For example, the average value of GETS for the level 1 applied force (F1) is calculated by averaging the trials with F1 force (trials 1, and 7). Figure 6 shows the average results for the GETS, GEB and HARD, it can be observed the inflaence for each parameter at the each level.

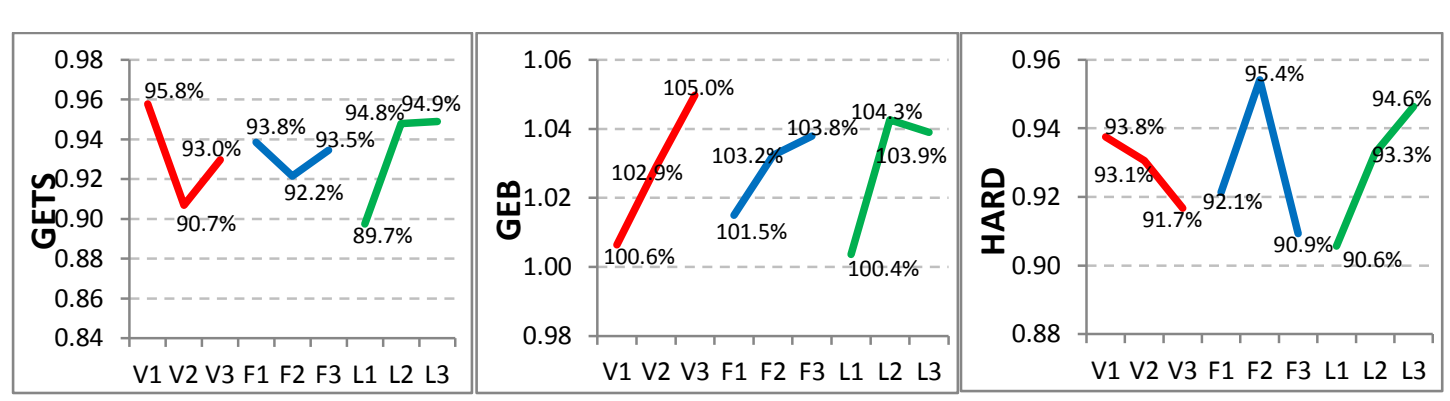

Figure 6. Effect of the Process Parameters on the GETS, GEB and HARD

In the GETS analysis, it has been observed that the lower advancing speeds in the welded samples will give a better behavior in these materials. The higher advancing speeds, the distortion promoted by the process has made the samples more susceptible to tensile loads. The pin length is the most crucial parameter in this analysis where the lowest pin length seems to have the lowest performance from all studies. The lowest pin length is very susceptible to process conditions especially to the increased welding speed. From Figure 6 it can be observed that the best performances for the GETs were reached at the first level of 
advancing speed (A1), first level of applied force (B1) and third level of pin length (C3).

It can be observed that the GEB increases with the increasing speed and the GEB efficiency is usually better than the BM. The applied force has the same behavior as the advancing speed and it seems that in the tested forces the highest applied force is the one that gives better results. The pin length continues to be very important for this parameter however for the conditions tested as long as it can be guaranteed that the sample is processed in its full thickness it can be guaranteed a good performance on bending loads. Using the same logic as in GETS, it can be observed that the best performance for GEB was reached at the third level of advancing speed (A3), third level of applied force (B3) and second level of pin length (C2).

The HARD results show a trend with the increasing speed and pin length where there is a drop on the HARD efficiency. However, some of these results do not seem to be aligned with the FSW process characteristics and aluminium. The best performance for HARD was reached at first level of the advancing speed (A1), the second level of applied force (B2) and third level of pin length (C3).

ANOVA is a normalized statistical technique to calculate the contribution percentage of each parameter in the chosen performance factors. This technique has allowed the identification of the most significant parameters and quantifying their effect in the GETS, GEB and HARD factors. The ANOVA technique uses the total sum of squares deviations (SST) is calculated through the equation:

$$
\mathrm{SS}_{\mathrm{T}}=\sum_{\mathrm{k}=0}^{\mathrm{n}}\left(\mathrm{Y}_{\mathrm{i}}-\overline{\mathrm{Y}}\right)^{2}
$$

Where $n$ is the number of trials $(n=9)$, Yi s the experimental result for the Trial $i$ and $\bar{Y}$ is given by:

$\overline{\mathrm{Y}}=\frac{1}{\mathrm{n}} \sum_{\mathrm{i}=1}^{\mathrm{n}} \mathrm{Y}_{\mathrm{i}}$

The total sum of square deviations is composed by sum of square deviations for each process parameter (SSP) and by the sum of square deviation due to error (SSe). SSP can be calculated using the following equation.

$$
\mathrm{SS}_{\mathrm{P}}=\sum_{\mathrm{j}=1}^{\mathrm{r}} \frac{\left(\mathrm{SY}_{\mathrm{j}}\right)^{2}}{\mathrm{r}}-\frac{1}{\mathrm{~h}}\left[\sum_{\mathrm{i}=1}^{\mathrm{n}} \mathrm{Y}_{\mathrm{i}} \mathrm{I}^{2}\right.
$$

In which 2 represents on process parameter, $\mathrm{j}$ is the level of the parameter $\mathrm{P}, \mathrm{r}$ is the number of trials at each level for the parameter P and SYi is the sum of the experimental results involving the paraneter $\mathrm{P}$ at the level $\mathrm{j}$. The sum of the square deviations due to error is given by:

$$
\mathrm{SS}_{\mathrm{e}}=\mathrm{SS}_{\mathrm{T}}+\mathrm{SS}_{\mathrm{A}}+\mathrm{SS}_{\mathrm{B}}+\mathrm{SS}_{\mathrm{C}}
$$

The totar number of degree of freedom (DT) is given by $n-1$. The number of degrees of freedom for each parameter (DP) is given by $r-1$ and the variance for each parameter $(\rho P)$ is calculated using the following formula:

$$
\rho_{\mathrm{P}}=\mathrm{SS}_{\mathrm{P}} / \mathrm{SS}_{\mathrm{T}}
$$

The contribution percentages of each process parameter are shown in Figure 7. In both GETS and GEB analysis (Figure 7), it can be observed that the pin length is a determinant contributor to promote good performances in this sector. This factor is related to typical defects of the FSW, the root defect. Having even a small root defect can greatly decrease the resistance to tensile and bending tests. The second major contributor for both the properties is the advancing speed where this effect seems to affect the samples in different manners. The 
GETS factor seems to be better for lower speeds while the GEB seems to improve for higher speed rates. This different relationship is associated with the fact that these alloys are not affected by the heat released in the process.

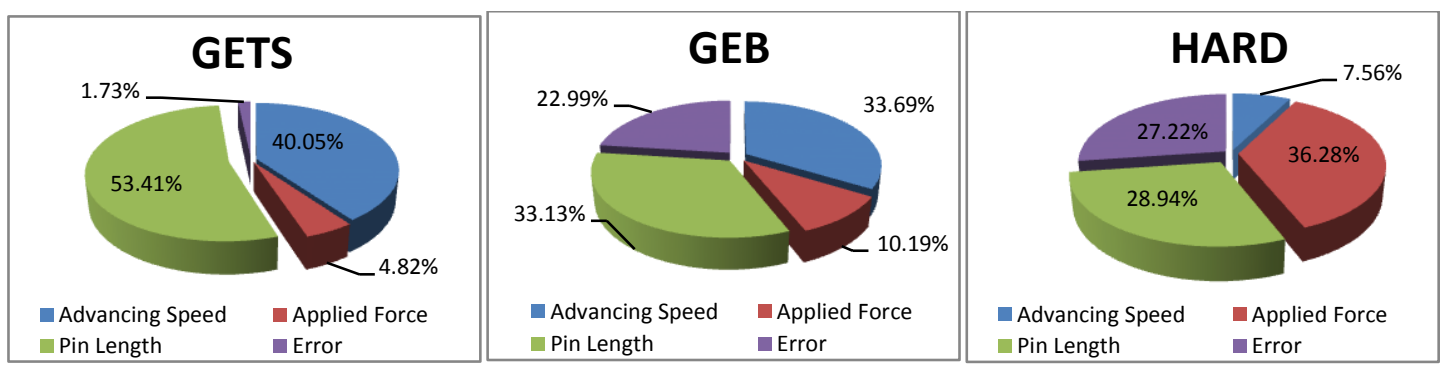

Figure 7. Influence of the Different Parameters in the GETS, GEB and HARD Efficiencies

The HARD factor is usually performed how the heat decreased the properties of the material in the heat affected zone. However, since these alloys are non-heat treatable this effect is reduced. Only for really high temperatures the reduction in hardness would be visible in these alloys. The applied force and pin length also have a smalleriffluence in this factor. One important conclusion of this factor is the high error (27 22\%) related to this parameter that can make some of the results be disregarded because of 10 The hardness was excluded from the following calculations.

After determining the optimal conditionfor each facto-(Figure 6) it is going to be predicted the performance for the established parametric combination, $Y_{\text {opt }}$ (Eq. 9). The quality characteristic the higher the value the better, the optimal parametric condition for maximizing the GETS factor is A1B1C3. The optimal perfornance of this factor can be established by the following relationship:

$\mathrm{Y}_{\mathrm{Opt}}=\frac{\mathrm{T}_{\mathrm{R}}}{\mathrm{N}_{\mathrm{R}}}+\left(\overline{\mathrm{A}}_{1}-\frac{\mathrm{T}_{\mathrm{R}}}{\mathrm{N}_{\mathrm{R}}}\right)+\left(\overline{\mathrm{B}}_{1}-\frac{\mathrm{T}_{\mathrm{R}}}{\mathrm{N}_{\mathrm{R}}}\right)+\left(\mathrm{C}_{3}-\frac{\mathrm{T}_{\mathrm{R}}}{\mathrm{N}_{\mathrm{R}}}\right)$

Where TR is the results total, NR the total number of results and $\overline{\mathrm{A}}_{1}, \overline{\mathrm{B}}_{1}$ and $\overline{\mathrm{C}}_{3}$ are the average values for the $\mathrm{A}, \mathrm{B}$ and $\mathrm{C}$ at the levels 1,1 and 3 respectively. Using the same procedure for GETS, the optinal performance of the GEB and HARD has been established.

Table 5. Optimal Values from Taguchi Method

\begin{tabular}{|c|c|c|c|c|c|c|}
\hline & \multicolumn{2}{|c|}{ GETS } & \multicolumn{2}{c|}{ GEB } & \multicolumn{2}{c|}{ HARD } \\
\hline Advancing Speed (mm/min) & A1 & 100 & A3 & 400 & A1 & 100 \\
\hline Force $(\mathrm{Kg})$ & B1 & 500 & B3 & 600 & B2 & 550 \\
\hline Pin Length (mm) & C3 & 2.09 & C2 & 2 & C3 & 2.09 \\
\hline Optimal Performance (\%) & \multicolumn{2}{|c|}{98.2} & \multicolumn{2}{|c|}{107.3} & \multicolumn{2}{|c|}{98.1} \\
\hline Confirmation Tests (\%) & \multicolumn{2}{|c|}{97.5} & \multicolumn{2}{|c|}{105.3} & \multicolumn{2}{|c}{} \\
\hline
\end{tabular}

Table 5 presents the confirmation tests made to confirm if the values predicted by Taguchi method were aligned with the actual performance of the process. It can be observed that the actual values are very close to the predicted ones and therefore Taguchi method can be successfully used in this alloys processed by FSW.

It was applied an algorithm that encloses in a measured way the different Taguchi results, to obtain a more robust parametric combination that globally improves the properties of the 
samples. For this goal, it was considered the contribution percentages for each parameter are based on the results obtained from the analysis of variance (Figure 7) and the optimal values for each process parameter (Table 5). The algorithm is presented as the following formula:

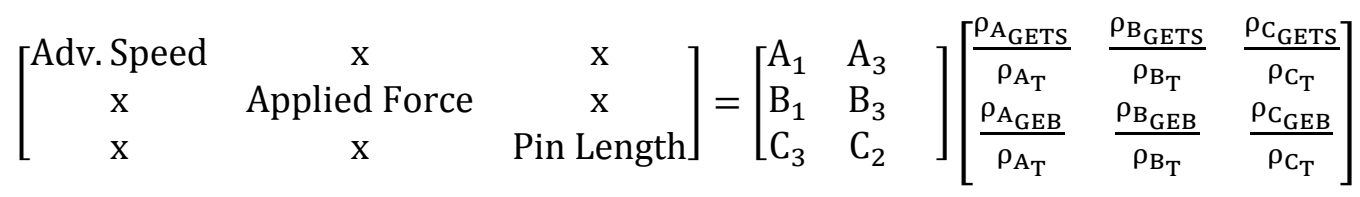

In this formula the contributions of the HARD factor have been removed due to its smaller influence on the properties of welded samples and this analysis will focus on the behaviour of the GETS and GEB parameters. This optimization method concludes that the best parameters are:

Advancing Speed $=237 \mathrm{~mm} / \mathrm{min} ;$ Applied Force $=567 \mathrm{~kg} ;$ Pin Length $=2.06 \mathrm{~mm}$

It has been confirmed that an AA5754 alloy processed with these parameters has a weld efficiency $98 \%$. This means that we are able to have welded samples with mechanical behaviours very similar to the base material mechanical behaviour and therefore can be successfully applied in these aluminium samples.

In order to understand the corrosion of the friction stir welded samples the samples were compared to the base material samples. The welded samples were tested on both sides to determine if the tested samples would have any preferential conrosion in these tests. Samples have been taken in predetermined interyals to observe the evolution of corrosion in these samples. These alloys seem to be very resistant to đlloys in fact they are usually used in saline environments. This alloy has been perceived as a good candidate to replace the AA5083 in its applications. It has been noted that no notorious differences in corrosion has been developed in the welded samples and that these have a similar behavior the base materials samples.

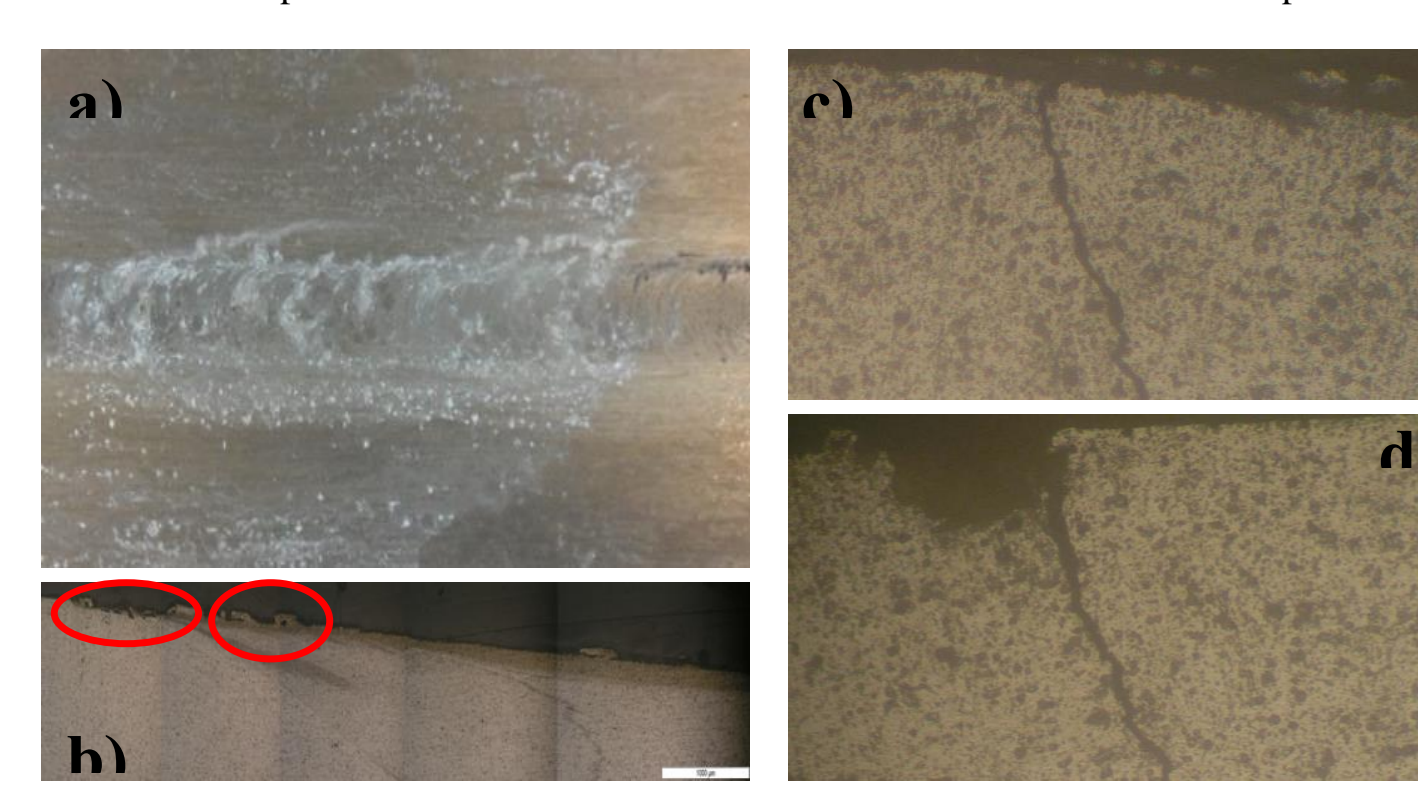

Figure 8. Samples Submitted to Corrosion Testing: a) Corroded Plate, b) Top of the Sample, c) Sample with Defect before Corrosion Testing and d) Sample with Defect after Corrosion Testing 
The surface of this processed is rougher than the rest of the sample and therefore it has a higher probability of suffering corrosion. It can be observed that there was no visible corrosion even in this section. In the back of the welded samples it was also confirmed the same behavior and also no preferential corrosion has been viewed along the weld line. In the same alignment (Figure $8 \mathrm{c}$ and $\mathrm{d}$ ) there a study has been performed to observe how an important defect such has the root defect has been studied. This defect usually negatively affects the tensile and fatigue properties of the welded samples. Some samples have been made to understand the influence of corrosion in these alloys.

It can be observed (Figure 8) that the corrosion of these aluminium samples is controlled and there is no clear preferential area of corrosion. In fact, it can be observed that there some spots that present corrosion but it is due to the roughness of the surface after being processed. In the samples with defect it can be clearly observed that the defect is a preferred area of corrosion in which a big corrosion hole is created due to the existence of this defect in its vicinity.

\section{Discussion of Results and Conclusions}

The Taguchi method has been confirmed to be a valuable method to identify the parameters that can optimize the properties of the welded materials. The effect of each parameter on the properties highlights which way one should ploceed to improve the properties of the material. To improve GETS efficiency, one should use small advancing speeds and forces. Because these alloys are not heat sensitive the higher speeds will induce residual strains in the joint material and the material will fracture much earlier than the joints with slower speeds. On the other hand, the best conditions for the GEB is better with the combination of faster advancing speeds and applied forces which will increase the hardness of the nugget and this improves a bitble resistance of the material to bending forces. The pin length is important in both these properties however it seems that the pin length over $2 \mathrm{~mm}$ is effective enough and eliminates the defects in this area.

The influence of the proces parameters in the hardness have been found to be quite the opposite of what usually happens in this process. This process has shown a tendency of the hardness to decrease with the increasing advancing speed. The hardness also is said to grow with the increasing length of the pin. These results are far from what really happens in the nugget. The increase in speed should be related with an increase in the hardness of the material because with the faster speed there is less heat released during the weld and therefore there would be a smalie effect in the hardness. The applied force and pin length should not have a big impact $m$ the hardness. These results do not make much sense because the aluminium is not heat-treatable and the released heat is not enough to produce an effective coalescence of the grain boundaries. Therefore, these hardness results were disregarded in the following steps in the selection of the optimal parameters.

It can-be observed that these alloys and have a very good corrosion resistance. It can also be viewed that the use of FSW does not affect the corrosion properties of the material and do not induce any preferential corrosion area. There is some corrosion in the rougher surface of the processed area and this is related to the rougher surface where the saline solution will concentrate and promote a more severe corrosion. The same fact happens in the "kissing bond" defect located on the root of the weld where the solution will concentrate there and the $\mathrm{Cl}$ - ions will react with the environment around it and promote a very severe corrosion. Has it can be seen the corrosion has promoted a very large hole in this area. Unlike the surface where the surface is a little bit rougher in the kissing bond defect the defect increases and the alloys much more susceptible to these defects. 


\section{Acknowledgements}

We would like to acknowledge the Foundation for Science and Technology (FCT), Lisbon, through the $3^{\circ}$ Quadro Comunitário de Apoio, and the POCTI and FEDER programmes. We also acknowledge FCT for the PhD scholarship SFRH/BD/33729/2009 supporting one of the authors, namely Filipe Nascimento.

\section{References}

[1] E. R. H. Fuchs, F. R. Field, R. Roth and R. E. Kirchain, "Strategic materials selection in the automobile body: Economic opportunities for polymer composite design”, Composites Science and Technology, vol. 68, 1989-2002, (2008).

[2] W. M. Thomas, E. D. Nicholas, J. C. Needham, M. G. Murch, P. Templesmith and C. J. Dawes, WO/1993/010935, International Patent Number PCT/GB92/02203, TWI, Improvements relating to friction welding, (1992).

[3] R. S. Mishra and Z. Y. Ma, "Friction stir welding and processing", Materials Science and Engineering R, vol. 50, (2005), pp. 1-78.

[4] F. Nascimento, T. Santos, P. Vilaça, R. M. Miranda and L. Quintino "Microstructuralmodification and ductility enhancement of surfaces modified by FSP in aluminium alloys", Materials Science and Engineering: A, vol. 506, (2009), pp. 16-22.

[5] P. Cavaliere, A. Squillace and F. Panella, "Effect of welding parameters on mechanical and microstructural properties of AA6082 joints produced by friction stir welding", Journal of materials processing technology, vol. 200, (2008), pp. 364-372.

[6] D. M. Rodrigues, A. Loureiro, C. Leitao, R. M. Leal,B. M. Chaparro and P. Vilaça, "Influence of friction stir welding parameters on the microstructural and mechanical properties of AA 6016-T4 thin welds", Materials and Design, vol. 30, (2009), pp. 1913-1921.

[7] P. Cavaliere, A. De Santis, F. Panella and A. Squillace, "Effect of welding parameters on mechanical and microstructural propertiesof dissimilar AA6082-AA2024 joints produced by friction stir welding", Materials and Design, vol. 30, (2009), pp. 609-616

[8] K. Elangovan and V. Balasubramanian, Influences of tool pin profile and welding speed on the formation of friction stir processing zone in AA2219 aluminiûm alloy", Journal of Materials Processing Technology, vol. 200, (2008), pp. 163-175.

[9] P. M. G. P. Moreira, T. Santos, S. M. O. Tàyares, V. Richter-Trummer, P. Vilaça and P. M. S. T. de Castro, "Mechanical and metallurgical characterization of friction stir welding joints of AA6061-T6 with AA6082T6", Materials and Design, vol. 30, (2009), pp. 180-187.

[10] S. T. Amancio-Filho, S. Sheikhi, J. F. dos Santos and C. Bolfarini, "Preliminary study on the microstructure and mechanical properties of dissimilar friction stir welds in aircraft aluminium alloys 2024-T351 and 6056T4", Journa of naterials processing technology, vol. 206, (2008), pp. 132-142.

[11] C. Vidal, V. Infante and P. Vilaca, "Assessment of Improvement Techniques Effect on Fatigue Behaviour of Friction Stir Welded Aerospace Aluminium Alloys”, Procedia Engineering, vol. 2, (2010), pp. 1605-1616.

[12] K. Lakshminarayanan and V. Balasubramanian, "Process parameters optimization for friction stir welding of RDE-40 aluminiupnalloy using Taguchi technique", Trans. Of nonferrous Met. Soc. China, vol. 18, (2008), pp. 548-554.

[13] P. Vilaça, "Fundamentos do Processo de Soldadura por Friç̧ão Linear - Análise Experimental e Modelação Analíticâ’, PhD Thesis, Instituto Superior Técnico, Universidade Técnica de Lisboa, (2003).

Corresponding Author: Filipe Nascimento, $\mathrm{PhD}$ candidate

Eaculdade de Engenharia da Universidade do Porto,

Design studio, Edificio $M$

Rua Doutor Roberto Frias s/n

4200-465 Porto, Portugal,

E-mail: f.nascimento@sapo.pt 